\title{
Report of Two Cases with Simultaneously Detected Tubular Carcinoma and Phyllodes Tumor of the Breast
}

\author{
(1) Burak İlhan ${ }^{1}$, (1) Selman Emiroğlu' 1 (1) Rüştü Türkay² \\ ${ }^{1}$ Department of Surgery, İstanbul Faculty of Medicine, General Surgery, İstanbul, Turkey \\ ${ }^{2}$ Clinic of Radiology, University of Health Sciences Turkey, Haseki Training and Research Hospital, Istanbul, Turkey
}

\section{ABSTRACT}

Tubular carcinoma (TC) is a subtype of invasive breast carcinoma with better prognosis, and phyllodes tumors (PT) are rare fibroepithelial lesions. Accurate preoperative pathological diagnosis allows for correct surgical planning and avoidance of reoperation for these breast neoplasms. A database was created by analyzing the archives of Department of General Surgery of the İstanbul Faculty of Medicine between September 2006 and November 2017, and a total of 105 PTs and 55 TCs were collected. Two cases with concurrence of TC and PT were identified and examined in detail. The first patient was a 33-year-old woman with a $20 \times 12 \mathrm{~mm}^{2} \mathrm{TC}$ and a $65 \times 32 \mathrm{~mm}^{2}$ malignant PT in the left breast. The second patient was a 28 -year-old woman with two masses in the right breast. The first mass was $38 \times 16 \mathrm{~mm}^{2}$ on the upper outer quadrant, and the second mass was $10 \times 8 \mathrm{~mm}^{2}$ in size in the lower inner quadrant, accompanied by a $16 \times 10 \mathrm{~mm}^{2} \mathrm{TC}$ and a $33 \times 26 \mathrm{~mm}^{2}$ borderline PT. Both cases were treated by mastectomies due to patient's decisions or insufficient margin control. This study extrapolated that if two tumors are detected simultaneously, margin control can become more difficult, and breast-conserving surgery should be thoroughly reviewed.
\end{abstract}

Keywords: Breast, phyllodes tumor, surgery, tubular carcinoma

Cite this article as: İlhan B, Emiroğlu S, Türkay R. Report of Two Cases with Simultaneously Detected Tubular Carcinoma and Phyllodes Tumor of the Breast. Eur J Breast Health 2021; 17(1): 80-83.

\section{Introduction}

Tubular carcinoma (TC) is a rare histologic subtype of all breast cancers, which accounts for $1 \%-4 \%$ of all breast carcinomas (1). Pathologically, TC appears like a necklace formed by a string of beads and presents with stellate infiltration. These tumors tend to be of low grade, which means that their cells appear normal, with $>90 \%$ of tubular formation. Over $90 \%$ of tumors with TC are hormone receptor positive and HER 2 negative, which indicates favorable oncologic outcomes (2-5).

Phyllodes tumors (PTs) are fibroepithelial breast tumors and account for less than $1 \%$ of all breast neoplasms (6). PTs have characteristic epithelial components arranged in clefts, surrounded by a mesenchymal component organized in a leaf-like pattern (7). Simultaneous occurrence of these two tumors is extremely rare.

\section{Case Presentations}

\section{Case 1}

A 33-year-old woman presented with a 1-year history of a rapidly enlarging left breast lump. Family history was significant for an aunt with breast cancer at age 60 years. Ultrasonography (USG) and mammography (MG) were performed as standard protocol. USG, MG, and additional magnetic resonance imaging detected two masses: a $24 \times 16 \mathrm{~mm}^{2}$ non-palpable lobulated mass in the lower outer quadrant and a $6 \times 5 \mathrm{~cm}^{2}$ mass in the upper inner quadrant with sharp margins (Figure 1). Multiple inconspicuous metastasis lymph nodes were detected in the axilla. Core needle biopsies were performed. The breast mass in the lower outer quadrant was diagnosed as TC, and the mass in the upper inner quadrant was diagnosed as mesenchymal neoplasia with core needle biopsy. A USG wire-guided tumor excision and a regular tumor excision were performed for the non-palpable first mass and second mass, respectively, based on the adequate breast volume and sentinel lymph node biopsy (SLNB) to the axilla. Under definitive pathologic examination, the mass found in the lower outer quadrant was a $20 \times 12 \mathrm{~mm}^{2} \mathrm{TC}$ without axillary lymph node metastasis (modified Bloom-Richardson Grade I). The tumor had luminal type A receptor features. No lymphovascular invasion (LVI) was detected. The mass in the upper inner quadrant was diagnosed as a $65 \times 32 \mathrm{~mm}$ malignant PT with 10/10 BBA mitosis score, marked cellular atypia, 
pleomorphism, and stromal overgrowth; however, this malignant PT was $5 \mathrm{~mm}$ close to the margin. Mastectomy was performed based on the surgeon's suggestion and patient's decision. Non-malignant postoperative changes were detected in the mastectomy specimen. Treatment continued with radiotherapy and anti-estrogen therapy. No further disease was observed in the 10-year follow-up period.

\section{Case 2}

A 28-year-old unmarried nulliparous woman presented with a 6-month history of a rapidly enlarging right breast lump. As regards family history, no ovarian or breast malignancy was determined. The masses were located in the right breast: the first mass $\left(38 \times 16 \mathrm{~mm}^{2}\right)$ was located on the upper outer quadrant (Figure 2 ) and the second mass $\left(10 \times 8 \mathrm{~mm}^{2}\right)$ was located in the lower inner quadrant. Core needle biopsies revealed that the first mass was a biphasic tumor and the second mass was a TC. Given the distant localization of these masses, mastectomy, SLNB, and oncoplastic surgery were performed on patient's request. The first mass was defined as a borderline PT $\left(34 \times 20 \mathrm{~mm}^{2}\right)$ and had 5/10 BBA mitosis score and minimal cellular atypia. The size of the TC was $14 \times 8 \mathrm{~mm}^{2}$ in definitive pathologic examination, which was a modified Bloom-Richardson grade I tumor. No LVI was detected. The tumor had luminal type A receptor features, and the SLNB result was negative. The patient was on anti-estrogen treatment. No further disease was observed in the 5-year follow-up period.

Informed consent was obtained from each patient for inclusion in this case report.

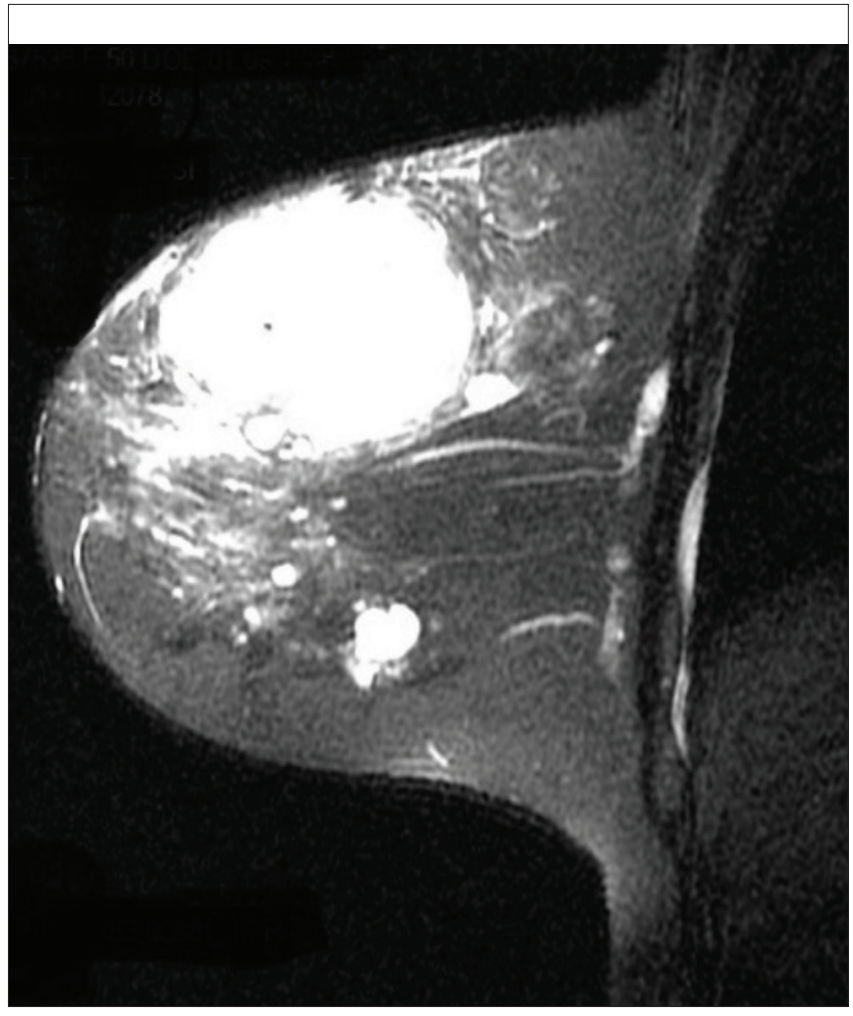

Figure 1. Malignant PT in the upper inner quadrant and TC in the lower outer quadrant

PT: Phyllodes tumor; TC: Tubular carcinoma

\section{Key Points}

- $\quad$ Simultaneous and co-detection of invasive breast cancer with PT of the breast is rarely described in the literature; however, the histogenesis has not yet been fully understood.

- If two breast tumors are detected simultaneously, margin control of both tumors can become more difficult.

- In this study, mastectomies were performed in one of the patients given the distance between the tumors and the other patient had positive margin, which supports the above opinion.

\section{Discussion and Conclusion}

Because TCs may have a typically favorable prognosis, efforts have been made to reduce unnecessary treatment. Therefore, some investigators have suggested that surgical staging of the axilla may not be necessary for $\mathrm{TC}<1 \mathrm{~cm}$. In contrast, other researchers have proposed that axillary staging should be considered for all patients with TC, as small tumors $<1 \mathrm{~cm}$ also showed nodal involvement (8). In our study, no nodal involvement was detected in both TC cases.

PT is one of the fast-growing breast tumors; however, it is generally histologically benign. It might remain latent for many years and then start to grow fast in some patients. MG and USG used in the diagnosis of breast masses are not very reliable in the differential diagnosis of PTs from fibroadenomas. Given the fast growth pattern, there might be suspicious axillary lymphadenopathies, enlargement in the skin and veins, nipple changes, and necrosis. Because of the similarity between PTs and fibroadenomas clinically and radiologically and for avoidance of any axillary procedure due to suspicious lymphadenopathies, preoperative evaluation with core biopsy for PT cases should be performed (8-13).

The underlying etiology for concomitant carcinoma occurring within PTs is unknown. The presence of carcinoma associated with PT is rare, with only anecdotal reports of isolated cases. Table 1 summarizes reports published since 2000, and most of the accompanying cancers were ductal carcinomas in situ (14-28).

Surgery is essential in the treatment of PTs, and wide excision with negative surgical margins (at least $1 \mathrm{~cm}$ ) is the recommended surgical approach regardless of the histopathological type (16). Surgical approach and margin assessment for TC is similar to invasive ductal carcinoma. In 2016, the Society of Surgical Oncology and American

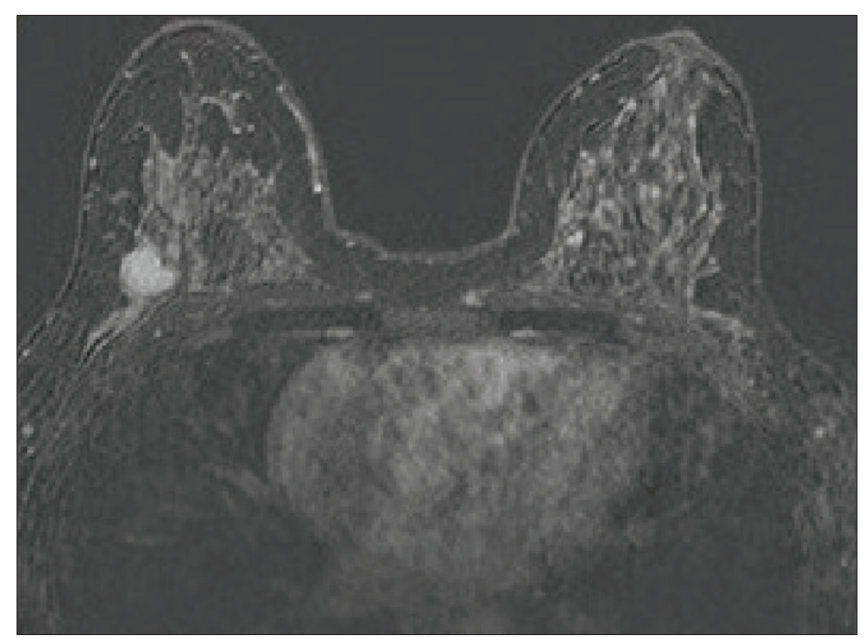

Figure 2. A borderline phyllodes tumor in the right breast 


\section{Table 1. Published literature of invasive and in situ carcinoma associated with PT}

\begin{tabular}{lllllll} 
No & Age & Type of PT & $\begin{array}{l}\text { Size of PT } \\
(\mathbf{c m})\end{array}$ & Type of carcinoma & $\begin{array}{l}\text { Lymph node } \\
\text { involvement }\end{array}$ & Study \\
\hline 1 & 39 & M & 9 & DCIS & 0 & Alo et al. (14) \\
2 & 47 & B & 17 & ILC & 0 & Kodama et al. (15) \\
3 & 26 & B & $3 / 3$ & IDC/DCIS & $4 / 13$ & Parfitt et al. (16) \\
4 & 45 & M & 12 & DCIS & 0 & Lim and Tan (17) \\
5 & 59 & M & $3 / 5$ & Undifferentiated & 0 & Tokudome et al. (18) \\
6 & 69 & B & NA & SCC & 0 & Ramdass and Dindyal (19) \\
7 & 75 & M & $3 / 5$ & DCIS & 0 & Nomura et al. (20) \\
8 & 65 & M & 6 & IDC & 0 & Sugie et al. (21) \\
9 & 51 & M & 16 & IDC/DCIS & $2 / 12$ & Korula et al. (22) \\
10 & 54 & B & 15 & DCIS & 0 & Yamaguchi et al. (23) \\
11 & 24 & Borderline & 10 & IDC/DCIS & $1 / 2$ & Kuo et al. (24) \\
12 & 70 & M & 6 & IDC & 0 & Macher-Goepinger et al. (25) \\
13 & 49 & B & $4 / 8$ & ILC/LCIS & 0 & Shirah et al. (26) \\
14 & 53 & Borderline & $6 / 5$ & IDC/LCIS & 0 & Qinlan-Davidson et al. (27) \\
15 & 42 & B & $2 / 2$ & DCIS & 0 & Ghosh and Saha (28)
\end{tabular}

M: Malignant P; B: Benign; IDC: Invasive ductal carcinoma; ILC: Invasive lobular carcinoma; DCIS: Ductal carcinoma in situ; LCIS: Lobular carcinoma in situ; SCC: Squamous cell carcinoma

Society for Radiation Oncology announced a margin consensus as "no ink on tumor" for invasive and $2 \mathrm{~mm}$ for ductal carcinoma in situ and reported the "no tumor at ink" principle as the standard for an adequate margin with wide excision (29). In this study, both patients underwent mastectomy.

Management steps of TCs and PTs separately are well-known; however, detecting these tumors simultaneously is extremely rare, and the histogenesis has not yet been fully understood. In our case, we could not reveal histomorphologic findings that would definitely support one of the theories suggested in the pathogenesis. However, we think that management can be more complicated in these cases with simultaneously detected different tumors. This study extrapolated that if two tumors are detected simultaneously, margin control can become more difficult and breast-conserving surgery should be thoroughly reviewed. The study has supported this opinion and the performance of mastectomies in both cases.

Informed Consent: Written informed consent was obtained from patients who participated in this case.

Peer-review: Externally peer-reviewed.

\section{Author Contributions}

Concept: B.İ.; Design: B.İ.; Supervision: B.İ.; Resources: B.İ., S.E., R.T.; Materials: B.İ.; Data Collection and/or Processing: B.İ., S.E.; Interpretation: B.İ., S.E., R.T.; Literature Search: S.E., R.T.; Writing Manuscript: B.İ.; Critical Review: B.I., S.E., R.T.

Conflict of Interest: The authors have no conflicts of interest to declare.

Financial Disclosure: The authors declared that this study has received no

\section{References}

1. Weiss MC, Fowble BL, Solin J, Yeh IT, Schultz DJ. Outcome of conservative therapy for invasive breast cancer by histologic subtype. Int J Radiat Oncol Biol Phys 1992; 23: 941-947. (PMID: 1322387) [Crossref]

2. Diab SG, Clark GM, Osborne CK, Libby A, Allred DC, Elledge RM. Tumor characteristics and clinical outcome of tubular and mucinous breast carcinomas. J Clin Oncol 1999; 17: 1442-1448. (PMID: 10334529) [Crossref]

3. McBoyle MF, Razek HA, Carter JL, Helmer SD. Tubular carcinoma of the breast: an institutional review. Am Surg 1997; 63: 639-644. (PMID: 24454462) [Crossref]

4. Lebeau A, Kriegsmann M, Burandt E, Sinn HP. Invasive breast cancer: the current WHO classification. Pathologe 2014; 35: 7-17. (PMID: 24496990) [Crossref]

5. Tan PH, TG, Lee A, Simpson JF, Hanby AM. Fibroepithelial Tumours. In: Lakhani SR, Ellis IO, Schnitt SJ, Tan PH, de V,jver MJ, editors. WHO Classification of Tumours of the Breast. $4^{\text {th }}$ ed. Geneva: WHO; 2012; 142-147.

6. Moinfar F. Biphasic tumors. In: Essentials of Diagnostic Breast Pathology: A Practical Approach, Heidelberg: Springer; 2007; 320-350.

7. Jacklin RK, Ridgway PF, Ziprin P, Healy V, Hadjiminas D, Darzi A. Review: Optimising preoperative diagnosis in phylloides tumour of the breast. J Clin Pathol 2006; 59: 454-459. (PMID: 16461806) [Crossref]

8. Deos PH, Norris HJ. Well-differentiated (tubular) carcinoma of the breast. A clinicopathologic study of 145 pure and mixed cases. Am J Clin Pathol 1982; 78: 1-7. (PMID: 6285690) [Crossref]

9. Buchanan EB. Cystosarcoma phylloides and its surgical management. Am Surg 1995; 61: 350-355. (PMID: 7893104) [Crossref]

10. Reinfuss M, Mitus J, Duda K, Stelmach A, Rys J, Smolak K. The treatment and prognosis of patients with phylloides tumour of the breast: 
An analysis of 170 cases. Cancer 1996; 77: 910-916. (PMID: 8608483) [Crossref]

11. Soyder A, Meteoğlu İ, Özbaş S. Phyllodes Tumour with simultaneous invazif duktal carcinoma in the ipsilateral breast. Eur J Breast Health 2008; 4: 49-52. [Crossref]

12. Kapiris I, Nasiri N, A'Hern R, Healy V, Gui GP. Outcome and predictive factors of local recurrence and distant metastases following primary surgical treatment of high grade malignant phylloides tumours of the breast. Eur J Surg Oncol 2001; 27: 723-730. (PMID: 11735168) [Crossref]

13. Chen WH, Cheng SP, Tzen CY, Yang TL, Jeng KS, Liu CL, et al. Surgical treatment of phylloides tumours of the breast: Retrospective review of 172 cases. J Surg Oncol 2005; 91: 185-194. (PMID: 16118768) [Crossref]

14. Alo PL, Andreano T, Monaco S, Sebastiani V, Eleuteri Serpieri D, et al. Malignant phyllode tumor of the breast with features of intraductal carcinoma. Pathologica 2001; 93: 124-127. (PMID: 11428289) [Crossref]

15. Kodama T, Kameyama K, Mukai M, Sugiura H, Ikeda T, Okada Y. Invasive lobular carcinoma arising in phyllodes tumor of the breast. Virchows Arch 2003;442:614-616. (PMID: 12743817) [Crossref]

16. Parfitt JR, Armstrong C, O'Malley F, Ross J, Tuck AB. In-situ and invasive carcinoma within a phyllodes tumor associated with lymph node metastases. World J Surg Oncol 2004; 2: 46. (PMID: 15601470) [Crossref]

17. Lim SM, Tan PH. Ductal carcinoma in situ within phyllodes tumour: a rare occurrence. Pathology 2005; 37: 393-396. (PMID: 16194856) [Crossref]

18. Tokudome N, Sakamoto G, Sakai T, Sarumaru S, Okuyama N, Hori F, et al. A case of carcinosarcoma of the breast. Breast Cancer 2005; 12: 149153. (PMID: 15858448) [Crossref]

19. Ramdass MJ, Dindyal S. Phyllodes breast tumour showing invasive squamous-cell carcinoma with invasive ductal, clear-cell, secretory, and squamous components. Lancet Oncol 2006; 7: 880. [Crossref]

20. Nomura M, Inoue Y, Fujita S, Sakao J, Hirota M, Souda S, et al. A case of noninvasive ductal carcinoma arrising in malignant phyllodes tumor. Breast Cancer 2006; 13: 89-94. [Crossref]
21. Sugie T, Takeuchi E, Kunishima F, Yotsumoto F, Kono Y. A case of ductal carcinoma with squamous differentiation in malignant phyllodes tumor. Breast Cancer 2007; 14: 327-332. (PMID: 17690514) [Crossref]

22. Korula A, Varghese J, Thomas M, Vyas F, Korula A. Malignant phyllodes tumour with intraductal and invasive carcinoma and lymph node metastasis. Singapore Med J 2008; 49: e318-321. (PMID: 19037540) [Crossref]

23. Yamaguchi R, Tanaka M, Kishimoto Y, Ohkuma K, Ishida M, Kojiro M. Ductal carcinoma in situ arising in a benign phyllodes tumor: report of a case. Surg Today 2008; 38: 42-45. (PMID: 18085361) [Crossref]

24. Kuo YJ, Ho DM, Tsai YF, Hsu CY. Invasive ductal carcinoma arising in phyllodes tumor with isolated tumor cells in sentinel lymph node. J Chin Med Assoc 2010; 73: 602-604. (PMID: 21093830) [Crossref]

25. Macher-Goeppinger S, Marme F, Goeppert B, Penzel R, Schirmacher P, Sinn HP, et al. Invasive ductal breast cancer within a malignant phyllodes tumor: case report and assessment of clonality. Hum Pathol 2010; 41: 293-296. (PMID: 27073506) [Crossref]

26. Shirah GR, Lau SK, Jayaram L, Bouton ME, Patel PN, Komenaka IK. Invasive lobular carcinoma and lobular carcinoma in situ in a phyllodes tumor. Breast J 2011; 17: 307-309. (PMID: 27073506) [Crossref]

27. Quinlan-Davidson S, Hodgson N, Elavathil L, Shangguo T. Borderline phyllodes tumor with an incidental invasive tubular carcinoma and lobular carcinoma in situ component: a case report. J Breast Cancer 2011; 14: 237-240. (PMID: 22031807) [Crossref]

28. Ghosh P, Saha K. Ductal carcinoma in situ in a benign phyllodes tumor of breast: a rare presentation. J Nat Sci Biol Med 2014; 5: 470-472. (PMID: 25097439) [Crossref]

29. Buchholz TA, Somerfield MR, Griggs JJ, El-Eid S, Elizabeth M, Hammond $\mathrm{H}$, et al. Margins for breast-conserving surgery with wholebreast irradiation in stage I and II invasive breast cancer: American Society of Clinical Oncology endorsement of the Society of Surgical Oncology/ American Society for Radiation Oncology consensus guideline. J Clin Oncol 2014; 32: 1502-1506. (PMID: 24711553) [Crossref] 